\title{
BURN PATIENTS;
}

Causes of death and factors affecting mortality a 4 years study at a tertiary care hospital

Dr. Firdous Khan, Dr. Asif Shah, Dr. Abdul Janan

ABSTRACT... Aim: To determine major risk factors of mortality and causes of death in patients presented with burn injury. Study design: Prospective Descriptive Study. Setting and duration: Department of Burns and Plastic Surgery, Khyber Teaching Hospital, Peshawar, Pakistan from April 2008 and June 2012. Methodology: A prospective descriptive study was performed among the patients who admitted to the Department of Burns and Plastic Surgery, Khyber Teaching Hospital, Peshawar, Pakistan between April 2008 and June 2012. All relative information was collected through a detailed proforma and patient's treatment files. Patients of any age, any degree of burns and burns exceeding 10\% TBSA were included. Patients presenting after more than one week post burn or patients referred from other hospitals were excluded. Within this period, demographic data, treatment, and outcomes of treatment were reviewed and analyzed. Survivors and non-survivors among burn patients were compared to define the predictive factors of mortality. Results: Between April 2008 and June 2012, 1850 patients were admitted with burn injuries. There were 1150 male patients (62\%) and 700 female patients $(38 \%)$. Mean age was 36 years with range of $1-70$ years. Inhalation injuries were present in 45 patients $(2.40 \%)$. Causes were flame burns $(65.0 \%)$, electrical burns (15\%), scalds (13\%) and chemical burns $(7.0 \%)$. The total body surface area (TBSA) burn ranged from $10-100 \%$, with a mean of $38 \%$ TBSA burn. Mean length of hospital stay was 12 days (ranging from 24 hours to 170 days). Mortality rate was $11.2 \%$. Higher age, larger burn area, wound infection, longer hospital stay and the presence of multi-system organ failure significantly predicted increased mortality. Conclusions: Prevention is a key factor in reducing the morbidity and mortality associated with burn injury. A campaign to educate people that burns can be prevented will be important in our community. The prevention of multiorgan failure and septicemia are likely to be more effective than their treatment.

Key words: Burn, Mortality, Hospital stay, Infection

Article Citation

Khan F, Shah A, Janan A. Burn Patients; Causes of death and factors affecting mortality a 4 years study at a Tertiary Care Hospital. Professional Med J 2013;20(6): 1042-1047.

\section{INTRODUCTION}

Burn injury is very common and affects approximately one per cent of the general population every year'. Burns account for $5 \%$ or more of the total hospital inpatients at any time $e^{2}$. In the developing countries, Burns poses significant social, public and medical problem to the families ${ }^{3}$. Burns are one of the most important causes of disability and mortality both in developed and developing countries ${ }^{4}$. The primary indicators of mortality in burns are advanced age, total body surface area (TBSA) involved and presence of inhalation injury ${ }^{5}$. Factors identified during the course of hospitalization also help to predict accurately the mortality of burns ${ }^{6}$. Burn causes more than 310,000 deaths per year ${ }^{7}$. In developing countries, death rate is estimated to be eleven times higher than in developed countries $^{8}$. The most danger effects of burns are pain, infections, scarring, wound contractures, amputations, psychological trauma and death ${ }^{9}$.
Complex fluid and metabolic changes are the main contributors to adverse outcome in severely burned patients ${ }^{10}$. The management of a burn patient needs special intensive care, equipment and well trained educated personnel ${ }^{11}$. Nowadays, mortality rates following burns have markedly decreased as a result of establishment of specialized burn centres, advances in critical care and anesthetic procedures, early excision and grafting, and use of topical and systemic antibiotics ${ }^{12}$. Since most burn injuries are accidental, the best way to reduce the incidence of burn injury is prevention by minimizing the risk factors and public awareness ${ }^{13,14}$.

We performed a prospective review in order to describe our population, compare results and analyze causes of death following burns at the Burns centre of Khyber Teaching Hospital (KTH) Peshawar catering to a large population from the Khyberpukhtonkhwa, Tribal 
areas and Afghanistan.

\section{MATERIALS AND METHODS}

A prospective descriptive study was performed among the patients who admitted to the Department of Burns and Plastic Surgery, Khyber Teaching Hospital, Peshawar, Pakistan between April 2008 and June 2012. All relative information was collected through a detailed proforma and patient's treatment files. Patients of any age, any degree of burns and burns exceeding 10\% TBSA were included. Patients presenting after more than one week post burn or patients referred from other hospitals were excluded. Survivors and non-survivors among burn patients were compared to define the predictive factors of mortality. Information was collected on age, sex, type of burn (flame, scald, chemical, or electrical), total body surface area affected, length of hospitalization, and presence of inhalation injury and causes of mortality.

The variables chosen to predict mortality during the hospital course included age, presence of inhalation injury, total burn area, development of infection, flame injuries, presence of multi-organ failure and length of hospitalization. Burn area was estimated from ageappropriate diagrams by one of the attending physicians. The total body surface area burned (TBSAB) was calculated from LUND \& BOWDER's chart, adding percentages of dermal and subdermal burns.

\section{RESULTS}

The burn patients were analyzed prospectively during 4-years period between April 2008 and June 2012. There were $68 \%$ male and $32 \%$ female. Mean age was 36 years with range of $1-70$ years. $88 \%$ of patients sustained burn injury accidently while 12\% were suicidal. Causes were flame burns (65.0\%), electrical burns (15\%), scalds (13\%) and chemical burns (7.0\%). The total body surface area (TBSA) burnt ranged from $10-100 \%$, with a mean of $38 \%$ TBSA burn. Mean length of hospital stay was 12 days (ranging from 24 hours to 170 days). Mortality rate was $11.2 \%$. Two hundred and fifteen (11.62\%) patients died during their stay in the burn unit. Fifty five patients (25.25\%) presented signs of severe infection at the time of death. The main contributing factors to death in patients without infection were Multisystem organ failure in 134 patients (62.32\%) and cardiorespiratory failure in 16 patients (7.44\%).

Non-surviving patients were significantly older and had larger burns. There were $37 \%$ deaths $(n=80)$ in children less than 2 years and $44 \%$ deaths $(n=95)$ in patients older than 50 years while only $19 \%$ deaths $(n=40)$ in patients between 2 and 50 years. Nonsurviving patients also stayed longer in the unit. With regard to the cause of burn, non-survivors suffered significantly more flame injuries and self-damage. Further, non-surviving patients needed more frequently catheters and blood transfusion. Also, nonsurvivors had significantly more infectious complications. Forty-five patients $(2.45 \%)$ had suffered severe inhalation injuries and were intubated; and only eleven of them survived while 34 patients (75\%) died. Higher age, larger burn area, wound infection, longer hospital stay and the presence of multisystem organ failure significantly predicted increased mortality. The characteristics of the patients are outlined in tables I and II and figures 1-4 below.

\begin{tabular}{|c|c|c|}
\hline TBSA \% Burnt & Cured / Discharged & Expired \\
\hline $10-20 \%$ & $655(35.40 \%)$ & - \\
\hline $20-30 \%$ & $405(21.89 \%)$ & - \\
\hline $30-40 \%$ & $290(15.67 \%)$ & - \\
\hline $40-50 \%$ & $210(11.35 \%)$ & $52(2.81 \%)$ \\
\hline $50-70 \%$ & $75(4.05 \%)$ & $63(3.40 \%)$ \\
\hline $70-100 \%$ & - & $100(5.40 \%)$ \\
\hline
\end{tabular}

Table-I. Outcome of patients with respect to TBSA\% burnt 


\begin{tabular}{|l|c|c|}
\hline Patient Characteristics & Survivors & Non-Survivors \\
\hline Hospital stay (days) & 11 Mean & 21 Mean \\
\hline Causes of Burn & & \\
Flame burns & $60 \%$ & $5 \%$ \\
Electrical burns & $11 \%$ & $4 \%$ \\
Scalds & $8.5 \%$ & $4.5 \%$ \\
Chemical burns & $4.5 \%$ & $2.5 \%$ \\
Inhalation injury & - & $2.4 \%$ \\
\hline Causes of death & - & $62.32 \%$ \\
Multisystem organ failure & - & $25.25 \%$ \\
Septicemia & - & $7.44 \%$ \\
Cardiac/respiratory failure & - & \\
\hline \multicolumn{2}{|l|}{ Table-ll. Characteristics of survivors and non-survivors } \\
\hline \multicolumn{2}{|l}{}
\end{tabular}

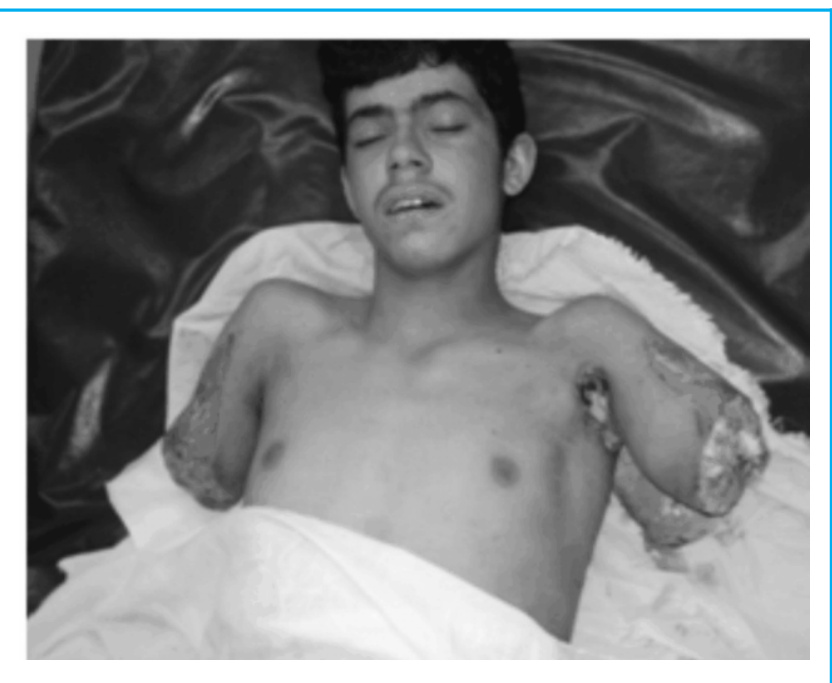

Figure-2. Age 15 male (Electrical burns 24\%)

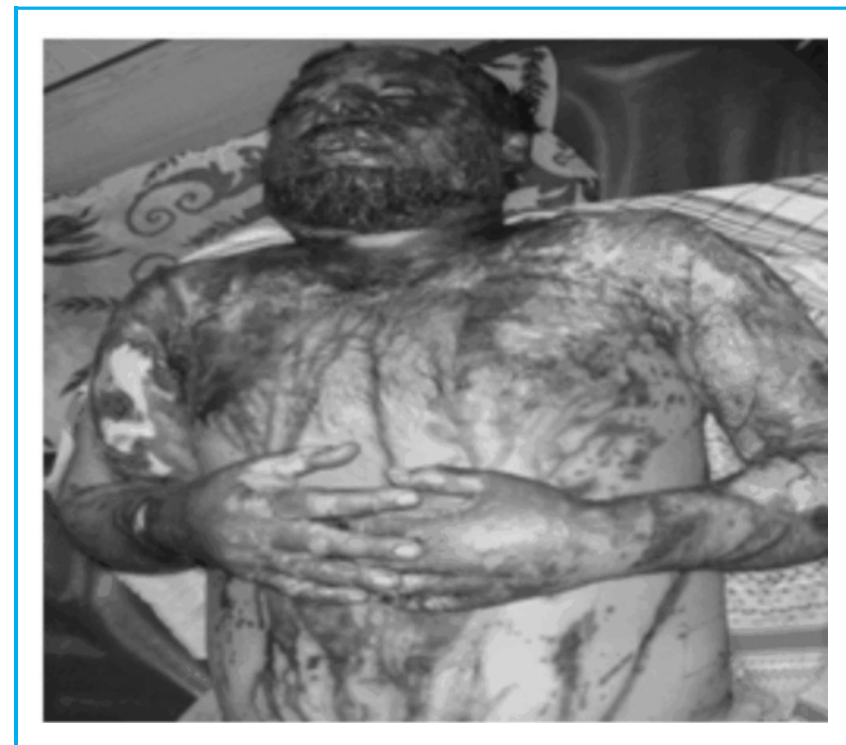

Figure-1. Age 45 male (Acid burns 45\%)

\section{DISCUSSION}

Burn injuries are the major health hazards leading to prolonged hospitalization and hence increased expense for the patients, their families and society ${ }^{15}$. The mortality is one of the most important outcome parameters following life-threatening trauma and may serve as a measure for quality of care ${ }^{12}$. It has been well established in the literature that burns by a direct flame, especially with smoke inhalation, percentage of total burned body surface and percentage of deep

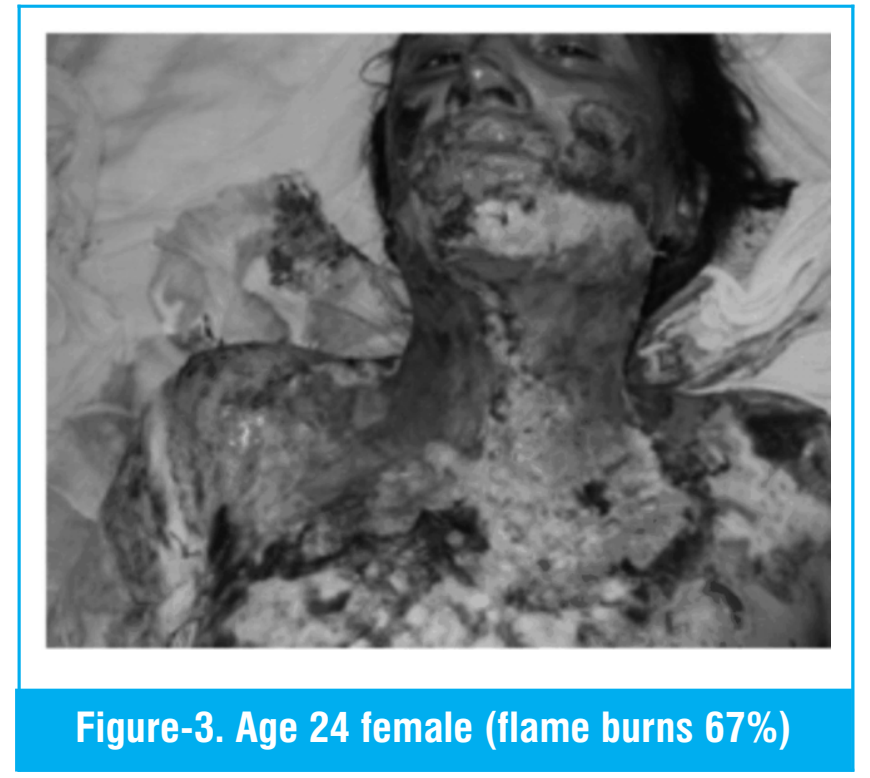

body surface burned and patient age are significant determinants of the prognosis of burn patients $s^{16,17,18}$. Several authors have proposed that different approaches to burn care may be meaningfully compared using patient age and total burn area as the cardinal determinants of burn mortality ${ }^{18}$. Initially, Bull and Squire defined their prediction of mortality after burn based on age and burn area ${ }^{19}$. 
According to the literature, multisystem organ failure is the leading cause of death ${ }^{20}$. Overtime, various reports have shown progressive improvement in mortality with advances in burn care ${ }^{21,22}$. Treatment in specialized burn centers has influenced survival after burns. New and innovative techniques such as early excision and grafting, institution of appropriate nutritional support, aggressive therapy for respiratory injury, and prompt recognition and treatment of burnrelated infections have played major roles in burn survival ${ }^{23}$.

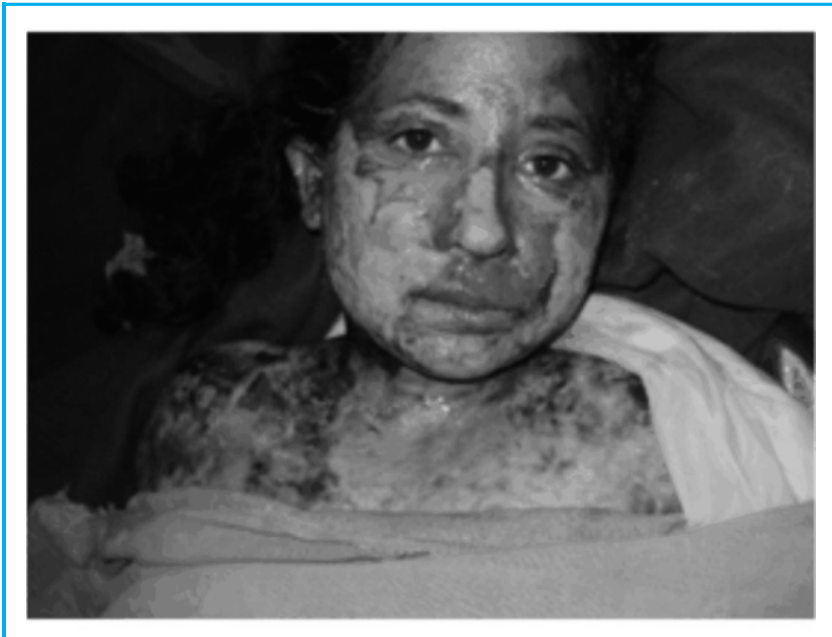

Figure-4. Age 12 female (flame burns 67\%)

Total Body Surface Area (TBSA) burnt is a highly significant variable affecting mortality as shown from our results as well.. The increasing severity of injury through more skin loss exposes the largest burns to more surgical operations and more complications, thus increasing mortality rate. With large burn area, the degree of skin loss renders the available donor skin area very small, and multiple operations using the same area as a donor site will be required to cover the entire, large wound area ${ }^{6}$.

We got $100 \%$ mortality in those patients having more than $60 \%$ TBSA burnt. The death rate in our study was $11.62 \%$ which is more than the overall $5 \%$ mortality rate. Our mortality rate is less than the death rate of
19.6\% reported in the Tohid burn centre in Tehran ${ }^{24}$. Mortality rate in our hospital was comparable to similar studies ${ }^{24,25,26}$. Flame, being the most common cause of burn in our study (65\%) is associated with more severe destruction of tissues and also accompanied by considerable immunosuppression making the patient prone to infection leading to high mortality ${ }^{27}$. The other major reason for the greater mortality in our patients is the lack of an intensive burns care unit. The lack of specialized intensive care unit leads to a delay in early tangential excision and skin grafting contributing to greater mortality ${ }^{28}$.

There is strong correlation between burn mortality and age of the patient as shown in the literature ${ }^{29}$. We got high mortality rate in children less than 2 years and older than 50 years comparable to similar studies ${ }^{22,29}$. Likewise, inhalation injury is also a strong predictor of mortality ${ }^{22,30}$. In patients with extensive burns, the comorbid effect of inhalation injury is largely obscured by that of the burn injury. We got $75 \%$ mortality in those patients having inhalation injury showing it a strong predictor of mortality. Similarly, the development of infectious complications in burns has been a significant cause of mortality ${ }^{31}$. Burn injury leads to immunosuppression and increased metabolic rate proportional to the extent of injury. The dysfunction of the immune system, a large cutaneous bacterial load, the possibility of gastrointestinal bacterial translocation, prolonged hospitalization and invasive diagnostic and therapeutic procedures, all contribute to sepsis, making the burn wound different from other forms of trauma ${ }^{23}$. According to reports, $75 \%$ of all deaths following burns are related to infection ${ }^{32}$. In our study, we came across 55 cases (25.25\%) of death due to sepsis. It is therefore necessary to carry out periodic review of patterns of isolation and susceptibility profiles of microorganisms infecting burn wounds in order to modify the preventive and therapeutic strategies for effective management of burn sepsis. This may also help to reduce mortality rate by preventing the colonization of microorganisms 
responsible for septicemia in different burn centers.

Multi-organ failure is one of the leading causes of increased mortality in burn patients. There are multiple foci of infections in burn patients leading to uncontrolled systemic inflammation, multi-organ failure and death ${ }^{20}$. In our study, multi-organ failure by flame burns caused the greatest number of deaths and was the deadliest among all the causes. This lethality is associated with respiratory lesions that increase the probability of death. In flame burns, total body surface area and inhalation injury are the predictors of death.

\section{CONCLUSIONS}

Prevention is a key factor in reducing the morbidity and mortality associated with burn injury. A campaign to educate people that burns can be prevented will be important in our community. The prevention of multiorgan failure is likely to be more effective than its treatment. The prevention requires early wound excision and closure to minimize wound sepsis and inflammation, support of the gut through enteral nutrition, and general hemodynamic support to ensure adequate oxygen delivery to the gut and peripheral tissues.

Copyright@ 15 Aug, 2013.

\section{REFERENCES}

1. Leistikow BN, Martin DC, Milano CE. Fire injuries, disasters and costs from cigarrettes lights, a global overview. Preventive medicine 2000; 31:91-9.

2. Bowen-Jones JR, Coovadia YM, Bowen-Jones EJ. Infection control in a third world burn facility. Burns 1990; 16: 445-8.

3. Uygur F, Sever C, Oksüz S, Duman H. Profile of selfinflicted burn patients treated at a tertiary burn center in Istanbul. J Burn Care Res 2009; 30: 427-31.

4. Barret JP. Epidemiology and mortality of adult burns in Catalonia. Burns 1999; 25: 325-9.

5. Tobiasen J, Hiebert J, Erdlich RF. The abbreviated burn severity Index. Ann Emerg Med 1982; 11: 260-2.
6. Macedo JLS, Santos JB. Predictive factors of mortality in burn patients. Rev Inst Med trop S Paulo 2007; 49: 365-70.

7. Forjuoh S, Gielen A. Burns. In: Peden M, Oyegbite K, Ozanne-Smith J, Hyder AA, Branche C, Fazlur Rahman AKM, et al. editors. World Report on Child Injury and Prevention. Geneva: World Health Organization 2008; PP: 79-98.

8. Mock C, Peck M, Peden M, Krug E. World Health Organization (WHO). A WHO Plan for Burn Prevention and Care. Geneva: World Health Organization 2008.

9. Anne HO, Hawa I, Lwidiko M, Mary JT, Naboth AM. Burns in Tanzania: morbidity and mortality, causes and risk factors: a review. Int J Burn Trauma 2013; 3 : $18-29$

10. Jeschke MG, Gauglitz G, Kulp GA, Finnerty CC, Williams $F N$, Kraft $R$, et al. Long-term persistence of the pathophysiologic response to severe burn injury. PLOS ONE 2011; 6: e21245.

11. Maghsoudi H, Pourzand A, Azarmir G. Etiology and outcome of burns in Tabriz, Iran: An analysis of 2963 cases. Scandinavian Journal of Surgery 2005; 94: 77-81.

12. Bloemsma GC, Dokter J, Boxma H, Oen IM. Mortality and causes of death in a burn centre. Burns 2008; 34 : 1103-7.

13. Gang RK, Bajec J. Electrical burns in Kuwait, a review and analysis of 64 cases. Burns 1992;18:497.

14. Lyngdorf $\mathrm{P}$, Sorensen $\mathrm{B}$, Thomsen $\mathrm{M}$. The total numbers of burn injuries in a Scandinavian population: a prospective analysis. Burns 1986; 12 : 567.

15. Hosseini RS, Askarian M, Assadian 0. Epidemiology of hospitalized female burns patients in a burn centre in Shiraz. Eastern Mediterranean Health Journal 2007; 13: 113-18.

16. Achauer BM, Allyn PA, Furnas DW, Bartlett RH. Pulmonary Complications of Burns: The Major Threat to the Burn Patient. Ann Surg 1977; 177: 311.

17. Pruitt BA, Tumbusch WT, Mason AD. Mortality in 1,100 
Consecutive Burns Treated at a Burns Unit. Ann Surg 1964; 159: 396.

18. Feller I, Flora JD, Bawol R. Baseline Results of Therapy of Burned Patients. JAMA 1976; 236: 1943.

19. Bull JP, Squire JR. A study of mortality in a burns unit: standards for the evaluation of alternative methods of treatment. Ann Surg 1949; 130: 160-173.

20. Sheridan RL, Ryan CM, Yin LM, Hurly J, Tompkins RG. Death in the burn unit: sterile multiple organ failure. Burns 1998; 24: 307-11.

21. Merrell SW, Saffle JR, Sullivan JJ, Larsen CH, Warden GD. Increased survival after major thermal injury: a nine year review. Amer J Surg 1987; 154:623-27.

22. Muller MJ, Pegg SP, Rule MR. Determinants of death following burn injury. BritJ Surg 2001; 88: 583-87.

23. Sharma PN, Bang RL, Al-Fadhli AN, Sharma P, Bang S, Ghoneim IE. Paediatric burns in Kuwait: incidence, causes and mortality. Burns 2006; 32: 104-11.

24. Rastegar LA, Alaghehbandan R, Nikui R. Epidemiological study of 3341 burns patients during three years in Tehran, Iran. Burns 2000; 26: 49-53.
25. Panjeshahin MR. Epidemiology and mortality of burns in the south west of Iran. Burns 2001; 27: 219-26.

26. Soltani K, Zand R, Mirghasemi A. Epidemiology and mortality of burns in Tehran, Iran. Burns 1998; 24: 325-8.

27. Bang RL. Burn septicemia. Burns 1998; 24: 354-61.

28. Merrel SW. The declining incidence of fatal sepsis following thermal injury. Journal of trauma 1989; 29 : 1362-6.

29. Wolf SE, Rose JK, Desai MH. Mortality determinants in massive pediatric burns: an analysis of 103 children with $>$ or $=80 \%$ TBSA burns $(>$ or $=70 \%$ full thickness). Ann Surg 1997; 225: 554-565.

30. Thompson PD, Herndon DN, Traber DL, Abston S. Effect on mortality of inhalation injury. J Trauma 1986; 26: 163-65.

31. Macedo JLS, Santos JB. Nosocomial infections in a Brazilian burn unit. Burns 2006; 32: 477-481.

32. Vindenes $\mathrm{H}$, Bjerknes $\mathrm{R}$. Microbial colonization of large wounds. Burns 1995; 21:575-9.

\section{AUTHOR(S):}

1. DR. FIRDOUS KHAN

Postgraduate Medical Officer,

Plastic Surgery and Burns Unit,

Khyber Teaching Hospital, Peshawar.

2. DR. ASIF SHAH

Senior Registrar,

Plastic Surgery and Burns Unit,

Khyber Teaching Hospital, Peshawar.

3. DR. ABDUL JANAN

Medical Officer,

Plastic Surgery and Burns Unit,

Khyber Teaching Hospital, Peshawar.

\section{Correspondence Address:}

\section{Dr. Firdous Khan}

Postgraduate Medical Officer,

Plastic Surgery and Burns Unit,

Khyber Teaching Hospital, Peshawar.

firdous25@yahoo.com

\section{PREVIOUS RELATED STUDIES}

Zulfiqar Ali Naqvi, Saleem A. Kharal, Qamar Aziz, BURN PATIENTS; EFFECTIVENESS OF $\beta$ LACTAM ANTIMICROBIAL DRUGS AGAINST GRAM NEGATIVE BACTERIA(Original) Prof Med Jour 18(2) 300-305Apr, May, Jun 2011. 